Volume 12 | Issue 3

October 2021

\title{
Community Journey of Change Through Relational Determinants of Health
}

Shelley Cardinal

Canadian Red Cross, Canada, shelley.cardinal@redcross.ca

Debra Pepler

York University, Canada, pepler@yorku.ca 


\title{
Community Journey of Change Through Relational Determinants of Health
}

\begin{abstract}
This article describes a model that maps Indigenous communities' journeys from the cycle of violence arising from colonization to the circle of wellness through relational determinants of health. This model emerged from learning with Indigenous communities participating in research on violence prevention programming with the Canadian Red Cross. Indigenous communities have shown us that they are returning to a place of thriving by restoring relationality with land, culture, ceremony, and language. Therefore, the relational determinants of health comprise the foundational relationships that contribute to wellness. The Community Journey of Change model represents actions that communities can undertake in moving to wellness. The model has implications for policies, programs, and services for Indigenous communities as they begin to restore health and wellness.
\end{abstract}

\section{Keywords}

violence prevention, Indigenous wellness, relational determinants of health, Indigenous communities

\section{Acknowledgments}

We acknowledge the work of all our team members, past and current, and gratefully recognize the contributions of Indigenous community members who shared knowledge and guided our work together. Dr. Kathy Absolon, Dr.

Susan Dion, and Dr. Onowa McIvor were important researchers helping to guide the Indigenous research methods, ethics, and meaning making. Judi Fairholm, Dr. Wendy Craig, and Sarah Burke helped us navigate through this complex project. We are grateful for the support of Angela Salamanca, the project coordinator who assisted with project logistics, Julia Riddell, who guided the qualitative analyses, as well as Sabina Bromley, who did years of work on the historical timeline. We are most grateful for the many community-based researchers including Stephanie Aulatjut, Curtis Bigeye, Joni Gibbons, Fran Hunt-Jinnouchi, Janice Moise, Nancy McFarland, Dawn-Lee Ricard, Laurie Sutherland, Phoebe Sutherland, and Tanya Smethurst. We also acknowledge the critical support of TerryLynn Beavereye, Terrellyn Fearn, Janice Morin, and Shirley Tagalik in helping establish and maintain the community partnerships. We appreciate the contributions of the research assistants Melissa Major, Stephanie McKenzie, Stephen Pepler, and Emily Melo. The understanding of Indigenous health from a Canadian perspective was co-developed by Dawn-Lee Ricard, Debra Pepler, and Shelley Cardinal. This research was funded through the Social Sciences and Humanities Research Council of Canada Partnership Grant \#895-2011-1013.

\section{Creative Commons License} (c) (1) (9)

This work is licensed under a Creative Commons Attribution-Noncommercial-No Derivative Works 4.0 License. 


\section{Community Journey of Change Through Relational Determinants of Health}

Since 1998, the Canadian Red Cross has been working with Indigenous communities in Canada to support them in capacity building and preventing violence in the lives of children and youth. Working with communities, Indigenous leaders, and allies, the Canadian Red Cross developed a suite of violence prevention programs for Indigenous communities. These programs focused on building awareness and capacity to promote safe environments for the healthy development of children and youth. The adult programs are grounded in the view that adults in the community have a responsibility to create safety for children and youth. Participants focus on developing a comprehensive understanding of historical and current forms of violence. Although the communities valued the violence prevention content, the workshops alone did not contribute to reduced violence within the community. This feedback led to the development of a community mobilization process.

Over the past 8 years, we have partnered with five Indigenous communities to study community mobilization processes: two First Nations reserve communities (in Saskatchewan and Ontario), two Inuit hamlets in Nunavut, and one urban Indigenous community represented through a Friendship Centre in British Columbia (Canadian Red Cross, 2009). We, Shelley Cardinal of the Canadian Red Cross and Debra Pepler of York University, have co-led this project. We acknowledge the work of all our team members, past and current, and gratefully recognize the contributions of Indigenous community members who shared knowledge and guided our work together. In this article, we integrate the relevant literature and our learning with communities to highlight a pathway for moving away from historical harm and systemic violence and toward a landing place of wellness that is relational.

Muskwas Nitanees, the Daughter of Little Bear, also known as Shelley Cardinal, is Cree and Mennonite. She was raised with stories of cultural strength and stories of the harms that Indigenous Peoples endured. From a young age, she knew her life work would contribute to addressing the harms. As a daughter of a Residential School Survivor and thriver, and an aunty to many, Shelley understands the power of strengthening culture and wellness. Today, she leads Indigenous relations, research, and engagement within the Canadian Red Cross. Debra Pepler lives and works on the Traditional Territory of the Wendat, the Anishnaabeg, Haudenosaunee, Métis, and the Mississaugas of the Credit First Nation. Her European ancestors came as uninvited settlers to Canada over a 150 years ago. She has been invited to be an ally and pursued a learning journey to understand the strengths of and challenges faced by Indigenous children and youth in the context of their families and communities. Debra is a mother, grandmother, and professor of psychology. Her teaching and research focus is child and youth development in family and peer relationships. Shelley and Debra met over 15 years ago, and they recognized a common interest in promoting relationships and preventing violence. Our collaboration began with a preliminary evaluation of the Canadian Red Cross Indigenous programming (Pepler \& Rubin-Vaughan, 2011), followed by a study of the processes that facilitators use to mobilize knowledge for Indigenous Peoples. We learned that the facilitators sought to deliver the program with fidelity, while balancing the needs of participants. They balanced the layers of harm being addressed with layers of safety (Yamada, 2014). These studies raised questions about the processes of program delivery, community capacity for health promotion, and systems supports needed to achieve and sustain community wellbeing. Communities highlighted gaps in violence prevention programming that focus primarily on understanding past and present violence. The programs seldom offer the advocacy and allyship needed to move beyond the harms and systemic barriers in order to enable communities to 
connect to a place of living in a healthy way grounded in cultural wellness. In this article, we present a model for communities' journeys to wellness through relational determinants of health.

\section{Challenges Indigenous Communities Face in Moving Toward Wellness}

The United Nations Declaration on the Rights of Indigenous Peoples (UNDRIP; UN General Assembly, 2007) acknowledged that Indigenous Peoples around the world have been oppressed, marginalized, and exploited because of historical and ongoing harms of colonization. These rights violations and inequities were formally recognized by the United Nations in 1982 based on work by the Working Group on Indigenous Populations examining discrimination faced by Indigenous Peoples throughout the world. In 2007, Ban Ki-moon, the United Nations secretary-general, stated that the UNDRIP was "a triumph for indigenous peoples around the world ... a historic moment when UN Member States and indigenous peoples reconciled with their painful histories and resolved to move forward together on the path of human rights, justice, and development for all” (Ban, 2007, para. 1).

Canada did not endorse UNDRIP until 2016, when the government stated:

[UNDRIP] provides us with a road map to advance lasting reconciliation with Indigenous Peoples. It shows us that further steps must be taken to respect, recognize, and protect the human rights of Indigenous Peoples and to address the wrongs of the past. (Government of Canada, 2016, paras. 1-2)

As in many countries around the world, there is much work to be done in Canada to meet the UNDRIP standards for Indigenous Peoples' rights. Indigenous communities in Canada have experienced chronic and multiple traumas since first contact, including displacement from Traditional Lands, devastation by diseases, subjugation under the Indian Act, banning of cultural practices, forced attendance at residential schools, child apprehension during the Sixties Scoop, and racist and systematic harms across many generations. The health of Indigenous children and youth has been identified as a critical issue in Canada: "After hundreds of years of colonial policies that intentionally eroded Aboriginal health care systems, First Nations, Inuit, and Métis children and youth lag behind their non-Aboriginal peers on virtually every measure of health status" (Blackstock et al., 2006, p. 3). ${ }^{1}$ Addressing historical harm contributes to community wellness. However, if imposed systems continue to foster oppression and marginalization, community resources are drained, making it difficult for communities to be in right relationship within their world in order to achieve balance and their full potential.

Indigenous children, youth, and adults thrive in a healthy relational environment. Therefore, our understanding of Indigenous health is that it comprises the physical, mental, emotional, and spiritual wellbeing of the whole community, whether urban, rural, or remote. ${ }^{2}$ Indigenous community health

\footnotetext{
${ }^{1}$ We have followed the guidance of Cyndy Baskin (2016) and others who use the term Indigenous, as opposed to the term Aboriginal, to refer to First Nations, Inuit, and Métis Peoples in Canada, as well as those around the world who are the original peoples on their lands. This collective noun is consistent with the United Nations Declaration of the Rights of Indigenous Peoples. When we quote directly, we have maintained the authors' original terms.

${ }^{2}$ This definition of Indigenous community health has been adapted from the Australian National Aboriginal Community Controlled Health Organization (2006).
} 
relies on foundational relationships with land, culture, ceremony, and language that contribute to wellness. We understand these as relational determinants of health.

For thousands of years, physical, mental, emotional, and spiritual relationships have created the foundations for Indigenous Peoples' strength, wholeness, and wellness. Communities helped us understand that their journeys to wellness involve recognition and restoration of the relationships that contribute to wellness. In their journeys, Indigenous communities are coming back to a place of thriving by restoring their relationality with land, culture, language, and ceremony. Therefore, we refer to the relational determinants of health as the foundational relationships that contribute to wellness.

In considering the determinants of Indigenous Peoples' health, de Leeuw et al. (2015) argued that understanding needs to extend beyond purely social determinants of health. They noted three shortcomings in the current knowledge:

a. Colonialism has yet to be accounted for as an important determinant of Indigenous Peoples' health,

b. Indigenous people's health should be examined as a unique area requiring different perspectives, and

c. Literature on the social determinants of Indigenous Peoples' health has been primarily written by non-Indigenous people.

According to de Leeuw and colleagues (2015), the term "social" is inadequate in describing factors that influence the health of Indigenous Peoples including: "spirituality, relationship to the land, geography, history, culture, language, and knowledge systems" (p.xii). We propose that these factors are foundational to relational determinants of health.

Reconnections to relational determinants of health occur within broader historical, political, societal, and economic systems that shape Indigenous Peoples' wellbeing and holistic health (Reading, 2018). Communities' journeys to wellness are constrained by these systems, which still operate from colonizing and Western perspectives that create marked inequities, limited opportunities, impoverished conditions, and discrimination. According to Reading (2018), these distal historical, political, ideological, economic, and social foundations create the context from which all intermediate and proximal social determinants arise. Therefore, Indigenous communities strive to mobilize to a place of thriving by restoring relationality, which can only be effective when systems within and beyond the community facilitate, rather than disrupt, the journeys to wellness.

\section{Programming in Indigenous Communities}

Community-based prevention programs for Indigenous populations can be effective in addressing a range of health challenges (e.g., Mussell et al., 2004; Rowan et al., 2014; Tsey et al., 2003). When programming is delivered at a community level, the community becomes the context for treatment (Jiwa et al., 2008). Research points to several defining features of effective violence prevention programming in Indigenous communities, including definitions of violence that recognize historical harms; strong community interest and engagement; community capacity building; community leadership in planning and delivery; recognizing culture as intervention and the role of Traditional Teachings and healing; inclusion of community, families, and individuals; coordinated service delivery; and sustainable 
resourcing and funding (Jiwa et al., 2008; Mussell et al., 2004). In developing Indigenous programming, the Canadian Red Cross has largely incorporated these elements. By studying the delivery of the Red Cross Indigenous programming, we have worked to understand the historical context, multigenerational trauma, and current suffering in communities with the goal of understanding the pathways away from violence.

In response to needs identified by communities, the Canadian Red Cross has partnered with Indigenous communities in preventing violence and promoting safe environments for children and youth for over 20 years. Canadian Red Cross programs have been developed with and for Indigenous communities that are seeking to understand and address challenges of violence. These programs promote understanding of the layers of historical harm, which are the foundation for current experiences of violence within communities. Community members come to understand, name, and re-claim the past, then begin the transition from the cycle of violence to wellness - a journey beginning with awareness and moving toward prevention. In a preliminary evaluation, we learned that this programming was valued by community participants and effective in communicating key messages about violence and abuse prevention (Pepler \& Rubin-Vaughan, 2011). Communities helped us understand that, although there was change in participants' understanding after the programming, it did not create a collective violence prevention response. To address this concern, the Canadian Red Cross (2009) developed a community mobilization process to create safe environments by:
a. Understanding the issue;
b. Recognizing the vulnerability and resilience of children and youth;
c. Defining protection instruments;
d. Creating a prevention team;
e. Completing a risk assessment;
f. Developing policies and procedures;
g. Educating adults, youth, and children;
h. Responding to disclosures of violence, abuse, bullying, and harassment;
i. Meeting community challenges around violence; and
j. Exploring how to maintain safe environments.

To support self-determination, there is an urgent need for Indigenous-led research on comprehensive, culturally relevant, and community-based violence prevention to understand what works, why it works, and what does not work. The Canadian UNICEF Committee (2009) report, Leaving No Child Behind, calls for "increased capacity-building initiatives for Aboriginal peoples to actively and effectively govern their own social, health, and education initiatives" (p. 9). In response to this need, we began our research partnerships to address the lack of knowledge about the implementation and effectiveness of violence prevention programming in Indigenous communities. In conducting our research, we recognized the need to work in a decolonizing, humble, and relational way that enables communities to return to balance and wellness. We were guided by diverse ethical frameworks and worked with communities to bring these ethical principles to life as they related to the diverse communities partnering in the research (Riddell et al., 2017). Our approach was grounded in respect, open communication, understanding responsibility and accountability, and ensuring learning in all places. 


\section{Developing a Model of the Community Journey of Change from the Cycle of Violence to the Circle of Wellness}

Through our partnerships, we have been working to identify, document, and understand community processes that address the cycle of violence rooted in colonization and promote wellness rooted in Indigenous traditions. As Indigenous and non-Indigenous scholars working with Indigenous leaders on community-based research, we sought to understand the processes that enable Indigenous communities to mobilize to promote individual, family, community, and cultural benefits. We also aimed to share knowledge within and beyond communities in Canada. We were focused on understanding communities' journeys to re-establishing health as they transition from the cycle of violence to community wellness. While working together toward a comprehensive evaluation of the violence prevention programming, we began to develop a conceptual model to describe the foundation for the work with Indigenous communities, based on the cultural framework of the First Nations Longitudinal Health Survey (Dumont, 2005).

As we engaged in research with communities, they guided us to recognize their needs for understanding, sharing, and self-documentation of the harms they have experienced. We also recognized the need for a compilation of reports from across Canada documenting the shared Indigenous story of colonial harms. For this historical documentation, we gathered information from over 1,000 sources including research, news media, Indigenous writing, government documents, films, etc. We developed a timeline of the harmful historical experiences that First Nations, Métis, and Inuit peoples endured through colonization in Canada: Pathways to Our Truths. The review revealed that harms were systematically layered for the purposes of power, control, greed, assimilation, and genocide. We organized the findings in a twodimensional chart with blocks of time since contact intersecting with experiences that began to coalesce into layers of harm. This chart reveals 15 layers of harm that accumulated to explain the deep and ongoing disruptions in community, family, and individual wellbeing. The layers of harm included disruptive experiences: contact, environmental dispossession, slavery and missing persons, dislocation, disease, substances, imposition of Christianity, residential schools, making and breaking of Treaties, Confederation, Indian Act and Aboriginal policies, police and criminal justice, pass system, Indian hospitals, and the Sixties and Millennial Scoops (Bromley et al, 2021). The review revealed that destructive layers of harm were planned and carried out based on previous layers of harm inflicted on Indigenous people. These layers of harm have cascaded, with accelerated disruption and dis-integration, increasing the burden of trauma over the past 500 years. This timeline is now being developed into a website for all Canadians and others to access and learn the truth about the harms from colonization. Having identified these layers of harm from the literature, we developed a Community Journey of Change model of the physical, mental, emotional, and spiritual harms arising from colonization over the past 500 years that still continue today. This model represents the pathways that communities can follow as they plan and travel away from the harms toward their journey to wellness by restoring and reintegrating the relational determinants of Indigenous health and wellness that have been disrupted by colonization.

With enhanced understanding from the timeline and from our experiences in communities, we depicted the cycle of violence that communities have struggled under, the circle of wellness that communities aspire to, and a sphere with cultural pathways that Indigenous communities have used in their journeys, represented by a canoe in motion, to reach the relational determinants of health (see Figure 1). Our 
knowledge gathering from the communities that participated in the violence prevention research has enabled us to develop the Community Journey of Change model. We are grateful to be able to integrate insights shared by community members to shed light on the meaning of the processes depicted in our Community Journey of Change model. These insights were from recorded share-back sessions with communities that participated in our Walking the Prevention Pathway research, funded by the Social Sciences and Humanities Research Council. For a description of the project and its methods, see Riddell et al. (2017).

\section{Cycle of Violence}

The stories that were generously shared in our research helped us to understand that every form of harm from colonization has created physical, mental, emotional, and spiritual violence and has disrupted all domains of Indigenous wellbeing. Colonization disrupted the foundational Indigenous way of being in all my relations, which Richard Wagamese (2016) discussed in his book Embers: One Ojibway's Meditations:

I've been considering the phrase 'all my relations' for some time now. It's hugely important. It's our saving grace in the end. It points to the truth that we are all related, we are all connected, we all belong to each other. The most important word is "all." Not just those who look like me, sing like me, dance like me, speak like me, pray like me, or behave like me. ALL my relations. That means every person, just as it means every rock, mineral, blade of grass, and creature. We live because everything else does. If we were to choose collectively to live that teaching, the energy of our change of consciousness would heal each of us-and heal the planet. (p. 36)

In depicting the cycle of violence, we distributed the 15 layers of harm identified in the timeline among the four domains by assigning the harm to the domain where its disruption is most prominent. We recognize, however, that each harm fits into each domain and its effects span domains. The cycle of violence illustrates the immense impact of historical harms on Indigenous Nations, communities, and Peoples. Although we began our research with a trauma-informed lens and a deep understanding of historical harms, we were overwhelmed by the breadth, depth, and longevity of harms emerging from the research and depicted within the integrated Pathways to Our Truths. The historical chart revealed a cascade of intentional harm and trauma. We were able to see how the cascade of harm gained intensity with each action by colonizers. As Dodge et al. (2009) described, "The metaphor of cascades, as in tumbling water that increases in speed and force as it is altered by, and alters, rocks in its path, captures some of the dynamic and transactional qualities" (p. 5). Indigenous Peoples' resistance to the intentional harm elicited quick and forceful reactions by colonizers to disrupt, displace, assimilate, and eradicate Indigenous Peoples in Canada. 
Figure 1. Community Journey of Change through Relational Determinants of Health

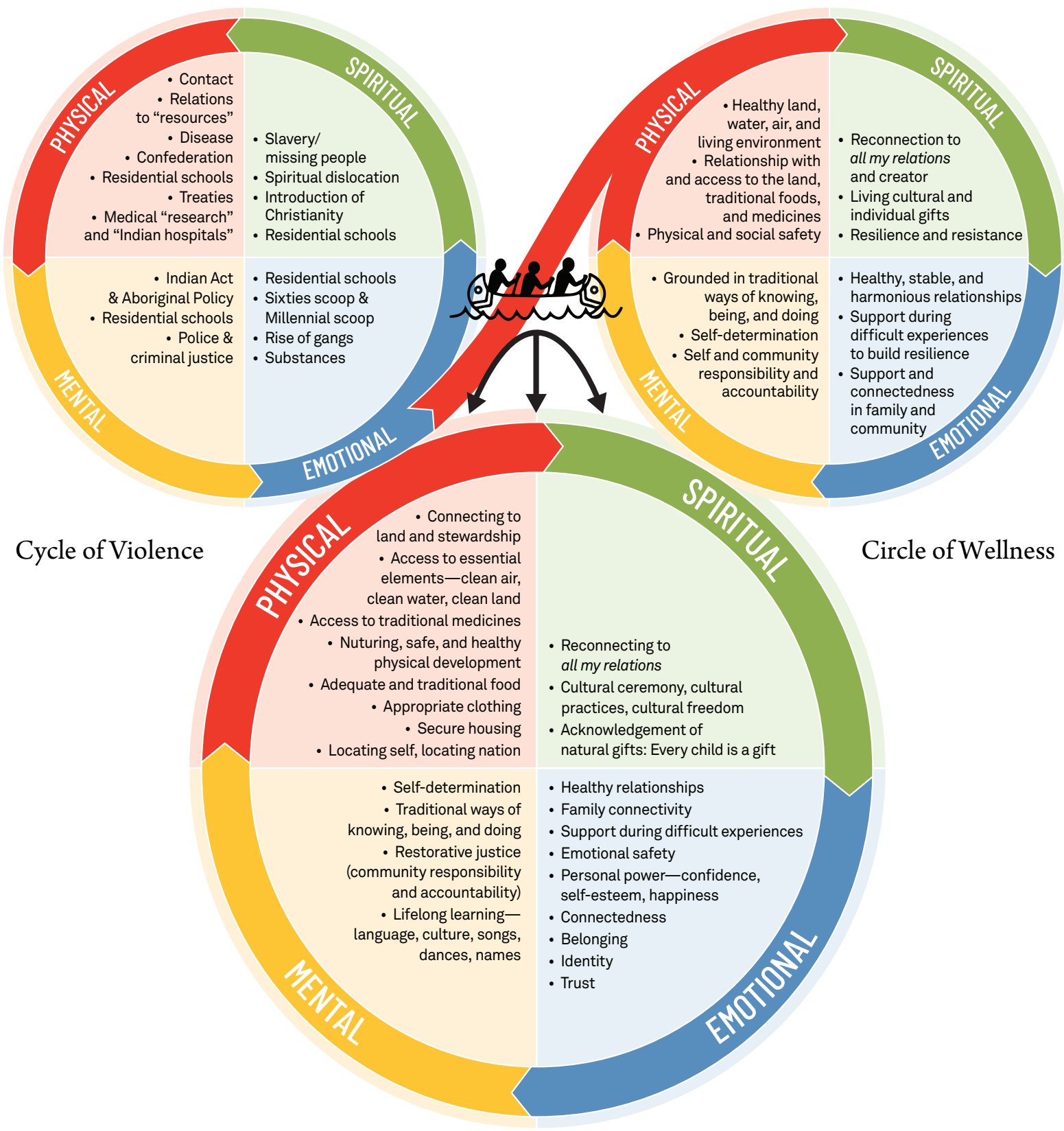

Relational Determinants of Health

Note. Copyright 2018 by Cardinal \& Pepler. 
The accumulation of layers of harm and trauma within Indigenous Nations, communities, families, and individuals continues to this day. As one of our community participants explained:

Because we're not [pause] we're already damaged, we're already broken, there's nothing to be broken anymore, we're just suffering ... We just need to, you know, help each other to heal and to move forward. (Community member) ${ }^{3}$

Another community member explained how the traditional ways of living and collectively solving problems of violence were disrupted by colonization:

Before all that happened, all this violence. If there was an incident that happened within the camps, it was dealt with by the family, by an Elder ... with a small group like a parent, an Elder and the person who was causing the problem ... And there was like ... everyone was connected ... And after colonization, that stopped ... People were trying to adapt I guess to the modern ... modern way of life and they lost their culture and their ways, their connections. (Hilary Irwin)

\section{Relational Determinants of Health}

With a view of the layers of harm and disruptions, we were then able to ask: What needs to be restored, repaired, re-placed, and re-integrated for the community journey to wellness? Based on our experiences of working with communities, we wondered how we could understand and support communities in effecting these restorations in today's reality. We examined each harm in the cycle of violence separately and were then able to consider the unique disruption caused by each harm for Indigenous Peoples. Within the model, we have labelled this healing process as restoring the relational determinants of health - the foundational relationships that contribute to wellness.

In identifying the journey that communities have used or may use to move from the cycle of violence to wellness, we have considered the determinants of Indigenous health from a relational perspective. With an understanding of the harms, it becomes possible to consider the interventions that counter the disruptions and support the journey of restoring the relational determinants of physical, mental, emotional, and spiritual health. These interventions form the basis of the communities' work in creating their journey through the relational determinants of health. For example, in the cycle of violence, there was dislocation from land and broken access to resources. In re-establishing relational determinants of health, the dislocation and disconnection can begin to be repaired by connecting individuals, families, and communities back to the land and providing access to essential elements: clean air, clean water, and clean land. The processes of reconnection to and repair of the land are complex and require consideration of governance, land ownership, and stewardship. Allowing stewardship to emerge entails interactive processes of recognizing whose Traditional Territory one is on, supporting the traditional stewards of the territory, finding space for one's own cultural activities and ceremony, and re-claiming the Indigenous right to hunt, gather, and secure traditional medicines. Shelley Cardinal explained: “This is something we all need to do. As a Cree woman living on Lekwangan Territory, I must always be

\footnotetext{
${ }^{3}$ For our knowledge gathering, we recontacted community members who shared their knowledge to ask permission to include their quote and to ask whether they wanted their names to be linked to their statements or whether they wanted to be identified as a "community member." We have attributed the quotes according to their wishes.
} 
cognizant that I am a guest and a visitor, and I need guidance on respectful Coast Salish practice" (personal communication, October 4, 2021). Indigenous Peoples see their relationship to the land as central to their wellbeing: "One of our Elders, Sophie Thomans from Saik'uz, said, 'If you take care of the land, the land will take care of you.' That's a very inclusive statement” (Teegee, 2018, p. 239). Sarah de Leeuw (2018) noted that land is separate from a social determinant of Indigenous identity and wellbeing: "Land ... is not enfolded into language culture, or spiritual values, but instead is 'reflected' in the sociological trait of being Aboriginal” (p. 191).

The journey through relational determinants of health highlights considerations for Indigenous communities as they reconnect and repair. This journey highlights many relational processes that may be constructive for recovery from the harms and disruptions of colonization. For example, in the mental domain, healing programming can promote self-determination; traditional ways of knowing, being, and doing; traditional justice; and learning the languages, songs, dances, and names that give meaning to and define each community's culture. Although Indigenous children, youth, and adults are embedded in the $21^{\text {st }}$ century, our work with communities has helped us understand that they are restoring balance by being bi-cultural and strengthening their Indigenous identities, meanings, and connections with culture. With culturally attuned supports, communities can mobilize away from the harms of colonization and onto pathways that re-create connections and enable movement toward health and wellness.

According to one community participant, the restoration of relational determinants of health with culturally grounded pathways has seldom been implemented:

Although there's been some different programs towards that, looking at the community from the top to find out what is really going on ... that has been done, several times by different organizations, prevention organizations, but one of the things that they always seem to forget is that how it was in the past with the Elders ... that's something that they always don't include in these ... programs. I may be wrong, but the prevention programs are always concentrating on the present day never ... from the past ... Because in the past things worked with families ... and what they are failing, I could be wrong but, what they, what they seem to be failing to do is put in that part into the programs. (Billy Ukutak)

\section{Circle of Wellness}

Wellness from an Indigenous perspective is a whole and healthy person expressed through a sense of balance of spirit, emotion, mind, and body. Central to wellness is belief in one's connection to language, land, beings of creation, and ancestry, supported by a caring family and environment. (Dumont, 2014, p. 2)

Through learning together with communities, we began to understand the journey through relational determinants of health and recognize that a relational lens is integral to the circle of wellness. We came to understand that if colonization had disrupted all my relations, then wellness could be conceptualized as a state of re-integrated all my relations. We considered general principles that would represent restoration of all my relations within the physical, mental, emotional, and spiritual domains. Within each domain, we identified three guiding principles for wellness (see Figure 1). The circle of wellness is selfdetermined by communities as they envision their landing place for wellness and ask questions such as: 
What are our common goals for wellness? Where do we come together to work on a common vision? What are our priorities in re-creating wellness within our community?

We learned from communities that the pathways through the relational determinants of health and the landing place of wellness need to be identified and led by the community and its members. Community members need to see and share a collective vision of a landing place for wellness in their community. The relational determinants of health indicate how communities can mobilize to restore their strong cultural foundations and provide clear guidance for interactions with systems both within the community and external to the community. Stronger relational determinants of health correspond to a stronger cultural foundation and self-determination. From this place, the community can provide greater direction to whatever is happening within or coming into the community. Restoring the relational determinants of health contributes to a shift in power dynamics - communities can engage in deep partnerships in which they are leading change to promote community health and wellbeing. By standing within their own culture, communities can identify the pathways through which to guide system change in ways that strengthen, rather than constrain, the relational determinants of health.

A community member who participated in the violence prevention programming explained:

I think the action plan in this process has brought light to the fact that there are people who can work together, so that the main tools that we can use are the tools of one another in different agencies, in different institutions and even just neighbours. (Chi-chi Arizne)

Another community member shared:

Whenever we go ask for help. They're always willing to help. So, it's the same thing with us ... Yeah. Like I said we're all striving for the same thing. We're all trying to keep the community safe and better for the youth, and just the overall community in general ... So I said that the motivation is still there. (Community member)

Within Indigenous communities, there is strong motivation and will for collective processes to restore health and move from the cycle of violence to the circle of wellness. As the Truth and Reconciliation Commission of Canada (TRC, 2015) revealed, repair, restoration, and reintegration are needed in many facets of the lives of Indigenous Peoples and communities. The Community Journey of Change model can guide organizations when invited to walk alongside Indigenous communities through the process of identifying their journeys to wellness. The cycle of violence highlights the violence and trauma experienced by Indigenous Peoples through colonization, which is not only historical, but ongoing and cascading. The relational determinants of health clarify processes for re-establishing disrupted Indigenous ways of knowing, being, and doing. The circle of wellness begins to provide clarity on the principles of wellness that communities can use to re-create their landing places for health and wellbeing. In this work, Indigenous Peoples can invite non-Indigenous peoples to walk alongside them in repairing and restoring the wellbeing, integrity, traditions, and relations of Indigenous individuals, families, and communities. 


\section{Considerations for Programs and Services with Indigenous Communities}

The Community Journey of Change model was informed by our research on the historical and ongoing harms of colonization for Indigenous Peoples in Canada. UNDRIP (2007) acknowledged similar harms experienced by Indigenous Peoples around the world who have "suffered from historic injustices as a result of, inter alia, their colonization and dispossession of their lands, territories and resources, thus preventing them from exercising, in particular, their right to development in accordance with their own needs and interests" (p. 3). Reparation for these harms can only be made with policies and practices that enable Indigenous communities to repair, re-place, and re-integrate what has been disrupted by colonization to meet their own needs and interests.

Given the disparate worldviews held within Indigenous and Western societies and their need to work together to restore balance and full rights for Indigenous Peoples, Ermine (2007) proposed a strategy of creating ethical space. Ethical space between Indigenous and Western systems requires engagement based on ethical and human principles, including humanity and respect. Ermine (2007) identified significant work to be done to create ethical space: "to step out of our allegiances, to detach from the cages of our mental worlds and assume a position where human-to-human dialogue can occur" (p. 202). As we have walked alongside communities in their journeys to restore wellness, they have helped us to understand that policies, programs, and services must align with principles of ethical space. It is only when Indigenous and non-Indigenous people can come together to work within ethical space that the barriers related to shame, guilt, inequities, and intergenerational trauma can be overcome.

Through our research, communities have guided us in identifying six considerations for creating ethical space in which to develop policies, programs, and services that support communities' journeys of change:

a. Look to Indigenous leaders for organizational alignment and Indigenous program development,

b. Respect self-determination and support community vision and actions (see also Barker et al., 2017),

c. Ensure safety at all levels and for all participants (Yamada, 2014),

d. Work to re-integrate culture (Dumont, 2014; Mussell et al., 2004),

e. Promote cohesion and culture within the community (Chandler \& Lalonde, 2008), and

f. Lead systems change (Reading, 2018; TRC, 2015).

Each of these considerations is briefly described below.

\section{Organizational Alignment with Indigenous Development}

Indigenous program development and service planning must be directed by Indigenous leaders. External organizations with an interest in working alongside and support communities in restoring wellbeing must embed Indigenous leaders within their organization. Only these leaders are able to frame the policies, programming, and services through an Indigenous lens. The core processes of addressing the cycle of violence and mobilizing communities toward wellness must be envisioned, developed, and delivered by Indigenous leaders at all levels of the organization. This is the only approach that will 
provide a strong foundation for the other considerations: self-determination, safety, culture, cohesion, and systems change.

\section{Self-Determination}

A community's vision of healing pathways and wellness is determined internally, not by an external program or service. Programs and services are often bound by deliverables; however, there has to be shared leadership and flexibility to meet communities' requests, visions, capacities, and paces of change. The communities need to lead their own healing processes and define their own landing place for wellness. To support self-determination, it is essential to ensure that external policies, programs, and services support Indigenous Peoples and communities and do not create dependency.

\section{Safety}

The layers of harm and trauma from colonization need to be counterbalanced with levels of safety (Yamada, 2014). Within community-based programs and services, we can ask: What safety mechanisms are in place to counteract the layers of harm and trauma? How can trust and safe relationships be created and sustained while working within the community? How can safety be created in delivering programs and services? It is imperative to ensure that policies, programs, and services do no harm and intentionally work to counteract and end the ongoing harms of colonization.

\section{Culture}

Re-integrating the cultural foundation that has been eroded is the key to beginning the journey to healing (Dumont, 2014). Cultural continuity within a community is linked to the health and wellbeing of its members (Chandler \& Lalonde, 2008). Ideally, effective community-based programs and services arise from within the community; however, in the context of today's reality, Indigenous communities often invite external programs and services to address harms. Any policy or program in an Indigenous community needs to make space for culture. The community has to lead the processes of capacity building and mobilizing for healing. The agency, program, or service, not the community, must be responsible for finding those who can inform the cultural elements to be embedded into policies, programming, and services.

\section{Cohesion}

Cohesion is about working with all my relations and deepening relations to land, culture, language, and people. Therefore, any healing process needs to be undertaken with a deep cultural consideration and by a collective, rather than an individual. Leadership from a community team can guide progress in protection policies and measures, prevention efforts, and crisis responses. The journey taken in moving from the cycle of violence toward the circle of wellness will necessarily be specific to each community and embedded within its culture.

\section{Systems Change}

Communities are not able to journey to wellness without significant shifts in Western structures that create and sustain social, economic, environmental, political, and cultural inequities, marginalization, 
and criminalization. Our historical timeline reveals the ongoing trauma from colonization. With the burden of historical and current harms, communities are caught between a deep commitment to leading their own healing process and pervasive harmful societal structures, policies, and practices.

The TRC (2015) focused on reparations related to the legacy of residential schools and presented Calls to Action for change in many systems within Canada including child welfare, education, language and culture, health, and justice. What systems changes are needed? These systems need to make room for natural Indigenous systems that worked well for millennia. Although self-determination is a guiding principle for journeying to wellness, it is difficult for Indigenous systems to operate independently from the broader social, economic, and political systems within the country.

\section{Moving Forward}

Our research with communities has enhanced our understanding of, not only the layers of violence and harm from colonization, but also how these have systematically fractured the foundational Indigenous principle of all my relations. We have learned from communities that the journey to wellness is grounded in re-integrating the fractured relational determinants of health and the cultural foundation of knowing, being, and doing in communities. Informed by the knowledge shared by communities, we are in the process of revising the violence prevention programming using our Community Journey of Change model so that it is Indigenized, re-integrative, and non-linear. This revised programming is being piloted and evaluated in communities across Canada. Although we are in the early stages of sharing the Community Journey of Change model, we have already heard from many community members about the important meaning and guidance provided by the model and programming based on it. One Elder shared:

What was meaningful for me was your explanation of the landing place. We are not thinking about our landing place and that provides a good guide for what we need to do. We need to define our landing place. (Community member)

Another community member explained:

My learning through the Community Change Journey massively increased my understanding of the role I play in my community and what my job is as a community connector. (Community member)

We believe that the Community Journey of Change model provides guidance to those working with and within diverse Indigenous communities to address the layers of harm from colonization and create culturally relevant pathways to restore the relational determinants of health. We are most grateful for the opportunities to work and learn with communities. We will continue to walk alongside and learn with Indigenous communities as they mobilize for their journeys of change and restore their relational determinants of health. 


\section{References}

Ban, K.-m. (2007, September 13). Secretary-General says Indigenous Rights Declaration 'triumph' for Indigenous Peoples around the world [Press release]. https://www.un.org/press/en/2007/ sgsm11156.doc.htm

Baskin, C. (2016). Strong helpers' teachings: The value of Indigenous knowledges in the helping professions. Canadian Scholars' Press.

Barker, B., Goodman, A., \& DeBeck, K. (2017). Reclaiming Indigenous identities: Culture as strength against suicide among Indigenous youth in Canada. Canadian Journal of Public Health, 108(2), e208-e210. https://doi.org/10.17269/cjph.108.5754

Blackstock, C., Bruyere, D., \& Moreau, E. (2006). Many hands, one dream: Principles for a new perspective on the health of First Nations, Inuit, and Métis children and youth. Canadian Paediatric Society. https://fncaringsociety.com/sites/default/files/manyhands-principles.pdf

Bromley, S., Cardinal, S., \& Pepler, D. (2021). A timeline of harm of colonization for Indigenous Peoples in Canada: Historical and ongoing cascades [Unpublished manuscript]. Department of Psychology, York University.

Canadian Red Cross. (2009). Ten steps to creating safe environments for children and youth: A risk management road map to prevent violence and abuse. https://www.redcross.ca/how-wehelp/violence-bullying-and-abuse-prevention/child-and-youth-serving-organizations/tensteps-to-creating-safe-environments

Canadian UNICEF Committee. (2009). Aboriginal children's health: Leaving no child behind. Canadian supplement to The State of the World's Children 2009. https://www.unicef.ca/sites/default/files/imce uploads/DISCOVER/OUR\%20WORK/AD VOCACY/DOMESTIC/POLICY\%20ADVOCACY/DOCS/Leaving\%20no\%20child\%20behi nd\%2009.pdf

Chandler, M. J., \& Lalonde, C. E. (2008). Cultural continuity as a protective factor against suicide in First Nations youth. Horizons, 10(1), 68-72.

https://www.researchgate.net/profile/Christopher_Lalonde/publication/239921354_Cultura 1 Continuity as a Protective_Factor_Against_Suicide in_First_Nations_Youth/links/561a cd8908ae6d1730898fe8.pdf

de Leeuw, S. (2018). Activating place: Geography as a determinant of Indigenous Peoples' health and well-being. In M. Greenwood, S. de Leeuw, \& N. Lindsay (Eds.), Determinants of Indigenous Peoples' health: Beyond the social( $2^{\text {nd }}$ ed., pp. 187-203). Canadian Scholars' Press.

de Leeuw, S., Lindsay, N., Greenwood, M., \& Reading, C. (Eds.). (2015) Determinants of Indigenous Peoples' health. Canadian Scholars' Press. 
Dodge, K. A., Malone, P. S., Lansford, J. E., Miller, S., Pettit, G. S., \& Bates, J. E. (2009). A dynamic cascade model of the development of substance-use onset. Monographs of the Society for Research in Child Development, 74(3), vii-119. https://doi.org/10.1111/j.1540$\underline{5834.2009 .00528 . x}$

Dumont, J. (2005). First Nations Regional Longitudinal Health Survey (RHS) cultural framework. First Nations Information Governance Committee.

Dumont, J. (2014). Honouring our strengths: Indigenous culture as intervention in addictions treatment. Thunderbird Partnership Foundation. https://thunderbirdpf.org/about-tpf/scopeof-work/honouring-our-strengths-culture-as-intervention-in-addictions-treatment/

Ermine, W. (2007). The ethical space of engagement. Indigenous Law Journal, 6(1), 193-203.

Government of Canada. (2016). Implementing the United Nations Declaration on the Rights of Indigenous Peoples in Canada. https://www.justice.gc.ca/eng/declaration/index.html

Jiwa, A., Kelly, L., \& Pierre-Hansen, N. (2008). Healing the community to heal the individual: Literature review of Aboriginal community-based alcohol and substance abuse programs. Canadian Family Physician, 54(7), 1000-1000.e7. https://pubmed.ncbi.nlm.nih.gov/18625824/

Mussell, B., Cardiff, K., \& White, J. (2004). The mental health and well-being of Aboriginal children and youth: Guidance for new approaches and services. Sal'I'shan Institute, Children's Mental Health Policy Research Program. https://childhealthpolicy.ca/wp-content/themes/chpc/pdf/RR-804-full-report.pdf

National Aboriginal Community Controlled Health Organisation. (2006). Constitution for the National Aboriginal Community Controlled Health Organization. https://f.hubspotusercontent10.net/hubfs/5328468/NACCHO_April_2020/PDFs/NACCH O-CONSTITUTION-Ratified-Ver-151111-for-ASIC-.pdf

Pepler, D., \& Rubin-Vaughan, A. (2011). Walking the prevention circle: A report for the National Crime Prevention Centre. Prepared for the Canadian Red Cross RespectED Programs.

Reading, C. (2018). Structural determinants of Aboriginal Peoples' health. In M. Greenwood, S. de Leeuw, \& N. Lindsay (Eds.), Determinants of Indigenous Peoples' health: Beyond the social ( $2^{\text {nd }}$ ed., pp. 3-17). Canadian Scholars' Press.

Riddell, J. K., Salamanca, A., Pepler, D. J., Cardinal, S., \& McIvor, O. (2017). Laying the groundwork: A practical guide for ethical research with Indigenous communities. International Indigenous Policy Journal, $8(2)$. https://doi.org/10.18584/iipj.2017.8.2.6

Rowan, M., Poole, N., Shea, B., Gone, J. P., Mykota, D., Farag, M., Hopkins, C., Hall, L., Mushquash, C., \& Dell, C. (2014). Cultural interventions to treat addictions in Indigenous populations: Findings from a scoping study. Substance Abuse Treatment, Prevention, and Policy, 9(1), 34. https://doi.org/10.1186/1747-597x-9-34 
Teegee, T. (2018). Take care of the land and the land will take care of you: Resources, development, and health. In M. Greenwood, S. de Leeuw, \& N. Lindsay (Eds.), Determinants of Indigenous Peoples' health: Beyond the social ( $2^{\text {nd }}$ ed., pp. 224-340). Canadian Scholars' Press.

Truth and Reconciliation Commission of Canada. (2015). Canada's residential schools: The final report of the Truth and Reconciliation Commission of Canada (Vol. 1). https://nctr.ca/records/reports/

Tsey, K., Deemal, A., Whiteside, M., \& Gibson, T. (2003). 'It's an eye-opener for people to see you can change things': An evaluation of a 'family wellbeing' personal and community development pilot project in two Cape York Communities. Apunipima Cape York Health Council. https://researchonline.jcu.edu.au/23746/

UN General Assembly. (2007). United Nations Declaration on the Rights of Indigenous Peoples (A/RES/61/295). http://www.un.org/development/desa/indigenouspeoples/wpcontent/uploads/sites/19/2018/11/UNDRIP_E_web.pdf

Wagamese, R. (2016). Embers: One Ojibway's meditations. Douglas \& McIntyre.

Yamada, S. A. (2014). Walking the prevention circle: Bearing witness to an Indigenous process for knowledge sharing [Doctoral dissertation, York University]. York University Library. https://yorkspace.library.yorku.ca/xmlui/bitstream/handle/10315/28236/Yamada_Samantha A 2014_PhD.pdf? sequence $=2 \&$ is Allowed $=y$ 